\title{
Análise técnica do corte semimecanizado do Angico (Anadenanthera colubrina (Vell.) Brenan)
}

\author{
Ana Karla Vieira da Silva ${ }^{1}$, João Lucas Rebouças de Oliveira ${ }^{1}$, Erick Daniel Gomes da Silva ${ }^{1}$, Rejane \\ Tavares Botrel ${ }^{1}$, Luciélia Lacerda da Silva ${ }^{1}$, Pompeu Paes Guimarães ${ }^{1}$
}

\begin{abstract}
RESUMO: Objetivou-se avaliar o corte semimecanizado do Angico em área de caatinga, em Mossoró. O método de seleção consistiu na classificação de três indivíduos por classe, quanto ao diâmetro a altura do peito (DAP). A coleta foi realizada por meio de observações visuais e descrição das atividades operacionais envolvidas no corte de angico, e do estudo de tempos e movimentos contínuos, através da cronometragem de cada atividade com auxílio de cronômetros, bem como o registro do tempo de trabalho efetivo e interrupções. O tempo total de atividade foi de 52,28 min. para o corte dos 15 indivíduos. O tempo médio para o abate foi de 0,74 min., enquanto o processamento de cada indivíduo ocorreu em média 2,30 min. As interrupções durante a atividade tiveram duração total de $6,55 \mathrm{~min}$. A classe 5 teve duração de 17,27 min para conclusão de toda atividade, seguida da classe 3, com total de 15,50 min. As demais classes, 1,2 e 4, demandaram menor tempo. O processamento consistiu na atividade em que demandou maior tempo para execução, seguida do abate e as pausas. Quanto ao tempo total subdividido por classe, as que exigiram maior tempo para realização do corte, foram as classes 5 e 3.
\end{abstract}

Palavras-chave: Estudo de tempos, motosserra, colheita florestal.

\section{Technical analysis of the semi-mechanized section of Angico (Anadenanthera colubrina (Vell.) Brenan)}

ABSTRACT: O The objective of this study was to evaluate the semi-mechanized cut of Angico in the Caatinga area, in Mossoró. The selection method consisted in the classification of three individuals per class, regarding the diameter of the breast height $(\mathrm{DBH})$. The collection was made through visual observations and description of the operational activities involved in the angico cut, and the study of times and continuous movements, through the timing of each activity with the aid of timers, as well as the recording of effective working time and interruptions. The total activity time was $52.28 \mathrm{~min}$. for the cut of the 15 individuals. The mean time to slaughter was $0.74 \mathrm{~min}$, while the processing of each individual occurred on average $2.30 \mathrm{~min}$. The interruptions during the activity had a total duration of 6.55 min. Class 5 lasted 17.27 min to complete all activity, followed by class 3 , with a total of $15.50 \mathrm{~min}$. The other classes, 1,2 and 4, demanded less time. The processing consisted in the activity in which it demanded more time for execution, followed by the slaughter and the pauses. As for the total time subdivided by class, those that required more time to perform the cut, were classes 5 and 3 .

Keywords: Time study, chainsaw, forest harvest.

\section{INTRODUÇÃO}

A utilização da Caatinga tem ocorrido sobretudo, em função da crescente demanda por combustíveis, a qual exige o manejo sustentável para produção de lenha e carvão. Entretanto, apesar do uso da vegetação da caatinga ocorrer de forma intensiva para fins energéticos, há escassez de informações acerca do processo de colheita de biomassas (SILVA, SAMPAIO, 2008).

A aplicação de sistemas de colheita florestal bem planejados, permite a racionalização, a organização e a otimização das atividades, colaborando para a melhoria da qualidade do produto e do serviço, bem como o aperfeiçoamento das condições de trabalho do homem, aumento de produtividade operacional e redução dos custos (FIEDLER et al., 2008).
Seixas et al. (2004), apontam o estudo de tempos e movimentos como sendo uma técnica fundamental no processo de colheita, uma vez que esta permite o conhecimento e a organização das atividades, com os objetivos de aprimorar o sistema operacional com redução nos tempos improdutivos, em concomitante com medidas ergonômicas, designar o empenho requerido para cada uma das atividades.

Diante do exposto, objetivou-se a avaliação técnica do corte semimecanizado do Angico, com vistas a demonstrar a metodologia de estudo de tempos e movimentos empregados na realização desta atividade em uma área de Caatinga.

\section{MATERIAL E MÉTODOS}


Foi avaliado corte semimecanizado do Angico em uma área nativa de Caatinga, no município de Mossoró/RN.

Inicialmente, realizou-se uma visita à localidade para demarcar os indivíduos que seriam abatidos, em um total de 15 . O método de seleção consistiu na

- Classe 2 - 12,59 a 18,49 cm;

- Classe $3-18,50$ a 24,49 cm;

- Classe 4-24,50 a 30,00 cm;

- Classe 5-acima de $30,00 \mathrm{~cm}$

Em uma segunda visita à localidade realizou-se a atividade de corte, ou seja, o abate e o processamento dos indivíduos. Toda a atividade foi realizada por um único operador, com o auxílio de uma motosserra.

A motosserra utilizada para a atividade de corte pertence à marca STHIL, modelo MS 170, 2017. Com cilindrada de $30,1 \mathrm{~cm}^{3}$, potência de $1,3 \mathrm{~kW}$ e peso de $3,9 \mathrm{Kg}$ (sem combustível e sem conjunto de corte).

A coleta de dados foi realizada por meio de observações visuais e descrição das atividades operacionais envolvidas no corte semimecanizado de angico, e do estudo de tempos e movimentos contínuos, através da cronometragem de cada atividade com auxílio de dois cronômetros de mão, bem como o registro do tempo de trabalho efetivo e das pausas e interrupções, com dados registrados em folha em branco (BARNES, 1977).

O número total de observações foi determinado pela Equação 1:

$$
n=\frac{\left(t^{2}+C V^{2}\right)}{E^{2}} \quad \text { (Equação 1) }
$$

Em que: $n=$ número mínimo de observações classificação de três indivíduos por classe, quanto ao diâmetro a altura do peito (DAP), correspondente aos critérios das classes diâmétricas:

- Classe 1-6,00 a 12,49 cm;

necessárias; $t=$ valor tabelado, para o nível de probabilidade desejado e (n-1) graus de liberdade; $C V=$ coeficiente de variação, em percentagem; $E=$ erro admissível, $5 \%$ da média, em porcentagem.

\section{RESULTADOS E DISCUSSÕES}

O número mínimo de amostras necessárias foram 9,76 indivíduos, enquanto o número coletado foi 15 , estando acima do valor mínimo da suficiência amostral.

O tempo total de atividade foi de 52,28 min. para o corte dos 15 indivíduos, a qual contou com atividades como abate, processamento dos indivíduos e interrupções.

O tempo médio para o abate foi de $0,74 \mathrm{~min}$ enquanto o processamento de cada indivíduo ocorreu em média 2,30 min. As interrupções registradas durante a atividade se caracterizaram por pausas resultantes do operador e banheiro, com duração total de 6,55 min.

Quanto ao tempo total das atividades por classe, a que exigiu maior tempo para realização de todo o processo foi a classe 5, com 17,27 min para conclusão de toda atividade, seguida da classe 3, com total de 15,50 min. As demais classes, 1, 2 e 4, demandaram menor tempo, 6,10, 4,82, 8,60 min. Entretanto, vale ressaltar que, durante o ciclo de operações das classe 3 , houve o maior tempo de pausa, com duração de 2,47 min (Tabela 2).

\begin{tabular}{lllll}
\hline \multicolumn{5}{l}{ Tabela 2. Tempos parciais por classe diâmétrica do corte semimecanizado de Angico. } \\
\hline Classes & Abate & Processamento & Pausas & Total (min) \\
\hline 1 & 3,37 & 1,85 & 0,88 & 6,10 \\
2 & 0,87 & 3,17 & 0,78 & 4,82 \\
3 & 2,25 & 10,78 & 2,47 & 15,50 \\
4 & 1,23 & 6,45 & 0,92 & 8,60 \\
5 & 3,45 & 12,32 & 1,5 & 17,27 \\
\hline
\end{tabular}

Fonte: Os autores.

Em relação ao tempo das atividades parciais, a atividade que demandou maior tempo foi o processamento de indivíduos, como encontrado por Lopes, Canto (2018); em um estudo de exploração de lenha da Caatinga em áreas com plano de manejo florestal sustentável.

Quanto as atividades parciais subdivididas por classes, o processamento dos indivíduos da classe 5 seguida da classe 3 , foi realizado em maior tempo. Enquanto a que teve menor duração de tempo, foi a classe 1, em média, para processamento de 1,85 min.
As demais classes, 2 e 4, tiveram 3,17 e 6,45 min, respectivamente.

No tocante a atividade de abate, a classe com maior tempo, em média, para realização da tarefa também foi a classe 5, dessa vez, seguida da classe 1, que mesmo sendo a classe com menor DAP, quando comparada com a classe 5 , demandou tempo semelhante. As demais classes, 2, 3 e 4, tiveram, em média, duração para abate de $0,87,2,25,1,23 \mathrm{~min}$.

Essa diferença de tempo entre as atividades de classes ocorreu, sobretudo, devido a diferença do DAP dos indivíduos, onde este estudo comprova que 
os indivíduos de maior DAP, alocados na classe 5, requereram maior tempo, enquanto que as atividades das classes 1 e 2, com menor DAP, ocorreram em menor espaço de tempo.

Outros fatores que podem ter influenciado nos tempos, são a inexperiência do operador da motosserra na realização do corte, relatado por Chaves (2016), como sendo esta a maior dificuldade encontrada para a realização da atividade de corte; e "enganchamento" da motosserra, citado por Pereira et al. (2012), em uma avaliação da segurança e ocorrência de defeitos na operação de corte semimecanizado de florestas de eucalipto, como um dos aspectos que resultou em elevado tempo na maioria dos tratamentos.

Leite et al. (2014), cita o espaçamento da vegetação como um dos fatores que influenciam no aumento do tempo da atividade corte, pois havendo dificuldade de acesso aos indivíduos, menor espaçamento, exigirá maior tempo para execução das atividades.

Quanto aos Tempos parciais, em porcentagem, por classe para o abate, o processamento e pausas (Figura 1), é possível observar que na classe 1 (a) houve maior demanda de tempo para abate, necessitando de $55 \%$ do tempo total para a realização da atividade. Seguidamente do processamento do indivíduo, que demandou aproximadamente $30 \%$ do tempo, havendo ainda 15 $\%$ do tempo total destinado à Seguidamente do processamento do indivíduo, que demandou aproximadamente $30 \%$ do tempo, havendo ainda 15 $\%$ do tempo total destinado à pausas. Nas demais classes 2 (b), 3 (c), 4 (d) e 5 (e), o processamento ocorreu em maior tempo. O abate ocorreu em tempo semelhante nas classes supracitadas, bem como o tempo para as pausas.

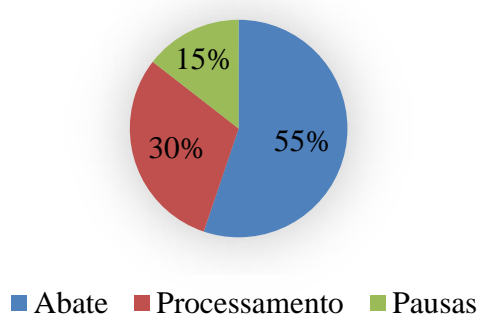

(a) Classe 1

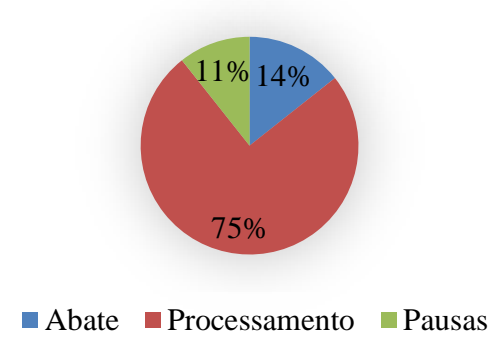

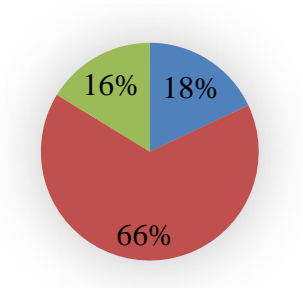

- Abate $\square$ Processamento $\square$ Pausas

(b) Classe 2

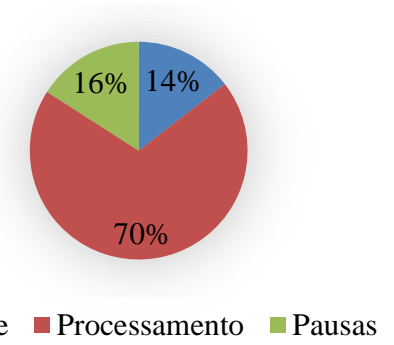

$\square$ Abate $\square$ Processamento $\square$ Pausas

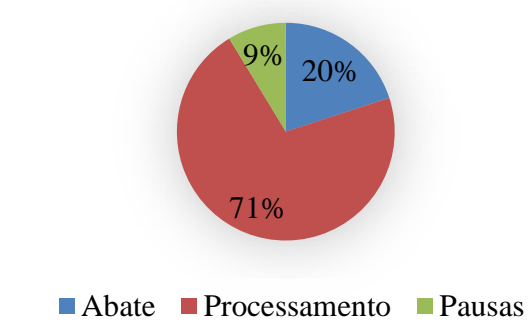

(c) Classe 3

(d) Classe 4

(e) Classe 5

Figura 1 - Tempos parciais, em porcentagem, por classe para o abate, o processamento e pausas.

\section{CONCLUSÕES}

Dentre as atividades parciais, o processamento consistiu na atividade em que demandou maior tempo para execução, seguida do abate e interrupções. Quanto ao tempo total das atividades por classe, as que exigiram maior tempo para realização de todo o processo foram as classes 5 e 3. As atividades referentes as classes 2, 1 e 4, ocorreram em menor tempo, respectivamente.

\section{REFERÊNCIAS}

BARNES, R. M. Estudos de tempos e movimentos: projeto e medida de trabalho. São Paulo: Edgard Blucher Ltda, 1977. 635p.
CHAVES, A. G. C. Diagnóstico da exploração de lenha em planos de manejo florestal sustentável na Caatinga do Rio Grande do Norte. 2016. 52 f. Dissertação (Mestrado em Ciências Florestais) - Universidade Federal do Rio Grande do Norte.

FIEDLER, N. C.; ROCHA, E. B.; LOPES, E. S. Análise da produtividade de um sistema de colheita de árvores inteiras no norte do estado de Goiás. Floresta, Curitiba, v. 38, n. 4, p. 577-586, 2008.

LEITE, E. S.; FERNANDES, H. C.; GUEDES, I. L.; AMARAL, E. J. Análise técnica e de custos do corte florestal semimecanizado em povoamentos de eucalipto em diferentes espaçamentos. Revista Cerne, Lavras, v. 20 n. 3, p. 637-643, 2014. 
LOPES \& CANTO. Produtividade e custos de dois sistemas de exploração e transporte de lenha na Caatinga. Nativa, Sinop, v. 6, n. 2, p. 207-212, 2018.

PEREIRA, R. S.; GUIMARÃES, P. B. R.; MENEZZI, C. H. S. D.; VALE, A. T.; ROBERT, R. C. G. Avaliação da segurança e ocorrência de defeitos na operação de corte semimecanizado de florestas de eucalipto. Revista Árvore, Viçosa, v. 36, n. 3, p. 511-518, 2012.

SEIXAS, F.; BARBOSA, R. F.; RUMMER, R. Tecnologia protege saúde do operador. Revista da Madeira, São Paulo, v. 14, n. 82, p. 68-73, 2004.
SILVA, G. C.; SAMPAIO, E. S. B. Biomassas de partes aéreas em plantas da caatinga. Revista Árvore, Viçosa, v. 32, n. 3, p. 567-575, 2008. 